\title{
Metabolic Syndrome, and Cardiovascular Risk among Mentally Ill Patients
}

\author{
M. Umakanth"1, T. Gadambanathan ${ }^{2}$ \\ ${ }^{1}$ Faculty of Health Care Sciences, Eastern University, Batticaloa, Sri Lanka \\ ${ }^{2}$ Batticaloa Teaching Hospital, Batticaloa, Sri Lanka \\ Email: mumakanth1972@gmail.com
}

How to cite this paper: Umakanth, M. and Gadambanathan, T. (2018) Metabolic Syndrome, and Cardiovascular Risk among Mentally Ill Patients. Journal of Biosciences and Medicines, 6, 72-79.

https://doi.org/10.4236/jbm.2018.68006

Received: July 26, 2018

Accepted: August 19, 2018

Published: August 22, 2018

Copyright $\odot 2018$ by authors and Scientific Research Publishing Inc. This work is licensed under the Creative Commons Attribution International License (CC BY 4.0).

http://creativecommons.org/licenses/by/4.0/ (c) (i) Open Access

\begin{abstract}
Patients with serious mental illness have an increased prevalence of the metabolic syndrome in comparison to the general population. Metabolic syndrome is a constellation of cardiovascular risk factors including diabetes, hypertension, obesity and dyslipidemia. It is potentially reversible and may explain the higher incidence of cardiovascular disease in patients with serious mental illness. The aim of the study is to see the prevalence of metabolic syndrome among mentally ill patients and what might be the underlying the cause behind the scene A descriptive, retrospective study was conducted at mental health clinic, Batticaloa, Teaching Hospital (BTH), Sri Lanka. The data were collected over a period of two months from 15th of October to 15th of December 2017. Data were harvested from the medical records. Total 55 mentally ill patient's medical records were analyzed for this study. Out of 55 , females were 30 (54.5\%) and males were 25 (45.5\%). Furthermore, 30 (54.5\%) patients had an evidence of metabolic syndrome. The association of metabolic syndrome among male and female was not statistically significant $(\mathrm{P}>$ 0.05). In this study, metabolic syndrome is more prevalent among, patient with trifluoperazine (70\%) drug group, risperidone (66.6\%) and olanzapine (53.12\%).
\end{abstract}

\section{Keywords}

Metabolic Syndrome, Cardiovascular Risk and Anti-Psychotic Medications

\section{Introduction}

Mentally ill health patients such as depression, schizophrenia, and bipolar disorders has been associated with wide range of metabolic derangement including metabolic syndrome and increased prevalence of cardiovascular risk such as ob- 
esity, dyslipidemia and diabetes or prediabetes. The prevalence of metabolic syndrome in patients with antipsychotic medications is higher than that seen in general population [1].

Metabolic syndrome is defined as a clustering of risk factors including cardiovascular risk and diabetes. Several criteria are for diagnosing metabolic syndrome. Metabolic syndrome is a set of risk factors that include abdominal obesity, a decreased ability to process glucose (insulin resistance), dyslipidemia and hypertension. Patients who have this syndrome have been shown to be at an increased risk of developing cardiovascular disease and type 2 diabetes.

Several organ systems are affected, including muscle, adipose, hepatic, nervous, and adrenal tissues, but from a clinical standpoint, the most important site of impact is the vasculature. Cumulative effects of classical risk factors such as pre-diabetes, dyslipidemia, and hypertension very likely contribute to increased risk of cardiovascular disease seen in individuals with the metabolic syndrome [2]. Insulin resistance is a major contributor to glucose intolerance, and the lipoprotein abnormalities seen in the metabolic syndrome are also expectable. Furthermore, with resistance to insulin, unrestrained lipolysis leads to increased delivery of free fatty acids to the liver for triglyceride (TG) synthesis and packing into very low-density lipoprotein (VLDL) particles. Higher VLDL levels contribute to lower HDL levels because of the reciprocal ex-changes between these lipoproteins mediated by cholesterol ester transfer protein [2].

The prevalence of overweight or obese in individuals with mentally ill patient has generally been believed to be greater than in individuals without the disorder [3]. However, regarding an increased risk for metabolic syndrome, not just obesity itself but rather increased central obesity or visceral adiposity is thought to pose the greatest risk for development of type 2 diabetes, dyslipidemias, and other cardiovascular complications [3]. A descriptive retrospective study was conducted by Umakanth $\mathrm{M}$ et al., which revealed that nearly two-thirds of the mentally ill population $29(63.1 \%)$ were found to be overweight $21(45.7 \%)$ and 8 (17.4\%) were obese [4].

According to guidelines used by National Cholesterol Education Programme expert panel on detection, evaluation and treatment of high blood cholesterol in adults (Adult Treatment Panel III) (NCEP-ATP III), metabolic syndrome consist of three or more risk factors out of following risk factors such as a waist circumference that measures at least 35 inches ( 89 centimeters) for women and 40 inches (102 centimeters) for men, high triglyceride level, $150 \mathrm{mg} / \mathrm{dL},(1.7 \mathrm{mmol} / \mathrm{L})$, or higher of this type of fat found in blood, reduced high-density lipoprotein (HDL) cholesterol, less than $40 \mathrm{mg} / \mathrm{dL}(1.04 \mathrm{mmol} / \mathrm{L})$ in men or less than $50 \mathrm{mg} / \mathrm{dL}$ $(1.3 \mathrm{mmol} / \mathrm{L})$ in women, increased blood pressure, $130 / 85 \mathrm{mmHg}$ or higher and elevated fasting blood sugar, $110 \mathrm{mg} / \mathrm{dl}$ or higher.

There are strong association between mental illness and metabolic syndrome including diabetes irrespective of whether patient taking antipsychotic or not. Compare with normal population, risk of developing metabolic syndrome in patient with mentally ill is twofold high [5]. The prevalence of metabolic syndrome 
varies with different countries it range from $3.6 \%$ to $68 \%$ [1]. Compare with older antipsychotics, atypical antipsychotics are less side effects and patients friendly and number of study proven it [3]. An interventional study conducted in UK, it has clearly shown that patient on haloperidol show more adipose tissue fat than those who were in olanzapine [5]. Another study conducted in Poland, compare with risperidone, olanzapine cause more metabolic derange. The aim of the study is to see the prevalence of metabolic syndrome among mentally ill patients and what might be the underlying the cause behind the scene.

\section{Methodology}

A descriptive, retrospective study was conducted at mental health clinic in the Batticaloa, Teaching Hospital (BTH), Sri Lanka. Data were harvested from the medicalrecords. The validated questionnaire was used to collect information of the patients. The questionnaire was pre-tested among 10 patients' data at mental health clinic at BTH. The changes were made where necessary to enhance comprehensibility and appropriateness. All most all the data were made available by the medical team when patients come with their relatives for their routine clinic visit. Even though most of mentally ill patients are stable mind with their medications, however demographic data were collected with help of their relatives. First part of the questionnaire contained questions related to demographic data including address, sex, age, body weight, waist circumference and BMI. Second parts of the questionnaire contained blood sugar, recorded blood pressure, triglyceride, total cholesterol and high-density lipoprotein levels. This was the routine blood checkup, doing regular basis at mental clinic. Each and every time, procedure was explained and got consent from the patients and relatives. As we did retrospective study based on patients' medical records, we did not contact with the patients or relatives. The data were collected over a period of two months from 15th of October to 15th of December 2017. We included all mentally ill patients with antipsychotic medications for at least three month of clinic follow-up. We excluded patients' age of less than 16 years and more than 69 years old, patients with inadequate data and patients with antipsychotic medications for less than three months duration.

BMI was further categorized into underweight $\left(\mathrm{BMI}<18.5 \mathrm{~kg} / \mathrm{m}^{2}\right)$, normal (BMI 18.5 to $24.9 \mathrm{~kg} / \mathrm{m}^{2}$ ), over-weight $\left(25.0\right.$ to $\left.29.9 \mathrm{~kg} / \mathrm{m}^{2}\right)$ and obese (BMI $\geq$ $30.0 \mathrm{~kg} / \mathrm{m}^{2}$ ). With available data metabolic syndrome was established as follows, it consist of three or more risk factors out of following risk factors such as a waist circumference that measures at least 35 inches ( 89 centimeters) for women and 40 inches (102 centimeters) for men, high triglyceride level, $150 \mathrm{mg} / \mathrm{dL},(1.7 \mathrm{mmol} / \mathrm{L})$, or reduced high-density lipoprotein (HDL), less than $40 \mathrm{mg} / \mathrm{dL}(1.04 \mathrm{mmol} / \mathrm{L})$ in men or less than $50 \mathrm{mg} / \mathrm{dL}(1.3 \mathrm{mmol} / \mathrm{L})$ in women, increased blood pressure, 130/85 mmHg or higher and elevated fasting blood sugar, $100 \mathrm{mg} / \mathrm{dl}$ or higher. The approval was taken from the head of the institution. All statistical analysis was performed using Statistical Package for Social Sciences (SPSS V.21). 


\section{Results}

Total fifty-five mentally ill patient's medical records were analyzed for this study. Out of 55, females were $30(54.5 \%)$ and males were 25 (45.5\%). Interestingly, more than $50 \%$ of mentally ill populations were in the age group of $30-49$. Furthermore, nearly half of the population $26(47.3 \%)$ were under category of over-weight and only 10 (18.2\%) were obese. Out of 55, 10 (18.2\%) patients were diagnosed as pre-diabetes and diabetes while, six (10.9\%) patients had hypertension. Moreover, 32 (58.2\%) of population had increased to talcholesterol (more than $200 \mathrm{mg} / \mathrm{dl}$ ), and 39 (70.9\%) of population had increased triglyceride (more than $150 \mathrm{mg} / \mathrm{dl}$ ). Patient were on various anti-psychotic medications, such as olanzapine $32(58.2 \%)$, risperidone 24 (43.6\%), and trifluoperazine 20 (36.4\%). In this study, metabolic syndrome is more prevalent among, patient with trifluoperazine (70\%) drug group than risperidone (66.6\%) and olanzapine (53.12\%). Finally, $30(54.5 \%)$ patients had an evidence of metabolic syndrome (Table 1). The association of metabolic syndrome among male and female were not statistically significant $(P>0.05)$.

\section{Discussion}

The Teaching hospital Batticaloa is the largest hospital in the eastern part of the Sri Lanka, it has well organized psychiatric unit and conducting twice a week clinic in the hospital. In both clinic around 100 mentally-ill patients are getting treatment in regular basis. This amount is fairly higher compare with other area of our eastern province. In this study, prevalence of metabolic syndrome among mentally ill patient is $54.5 \%$. However, the prevalence for the metabolic syndrome among the general population of US, adults is approximately $24 \%$ [2]. However, two cross-sectional studies revealed that $60 \%$ prevalence of metabolic syndrome was observed among schizophrenic patients and a $75 \%$ prevalence rate was estimated among mood disorder patients of Hispanic origin [6]. Furthermore, metabolic syndrome is highly prevalent in patients with schizophrenia with reported prevalence that ranges from $10.1 \%$ to $69.3 \%$ [6]. In Singapore, the prevalence of metabolic syndrome in the community had been reported to range from $17.7 \%$ to $26.2 \%$ [7]. Unfortunately, prevalence of metabolic syndrome in the normal population is not evaluated in Sri Lanka. However, in US and Singapore it was ranged from $17.7 \%$ to $26.2 \%$ [7]. Furthermore, prevalence of metabolic syndrome is increased by two-fold in mentally ill population. The reason behind this is mentally ill condition itself and medications. There is a considerable literature on the metabolic adverse effects of antipsychotic agents and, in particular, second generation antipsychotics (SGAs) appear to induce more weight gain and metabolic abnormalities than first generation antipsychotics (FGAs) [8]. However, in this study metabolic syndrome is more prevalence among trifluoperazine (70\%) drug group than risperidone (66.6\%) and olanzapine (53.12\%). Several studies revealed that, second generation antipsychotics has been associated with increased prevalence of metabolic syndrome [9]. 
Table 1. Sex, age, BMI, fasting blood sugar, total cholesterol, triglyceride, high density cholesterol, waist circumference, hypertension and metabolic syndrome percentage among mentally ill patients.

\begin{tabular}{|c|c|c|}
\hline Category & $\mathrm{N}$ & $(\%)$ \\
\hline \multicolumn{3}{|l|}{ Sex } \\
\hline Male & 25 & 45.5 \\
\hline Female & 30 & 54.5 \\
\hline \multicolumn{3}{|l|}{ Age } \\
\hline $20-29$ & 7 & 12.7 \\
\hline $30-39$ & 21 & 38.2 \\
\hline $40-49$ & 10 & 18.2 \\
\hline $50-59$ & 17 & 30.9 \\
\hline \multicolumn{3}{|l|}{ BMI } \\
\hline Under-weight & 6 & 10.9 \\
\hline Normal & 13 & 23.6 \\
\hline Over-weight & 26 & 47.3 \\
\hline Obese & 10 & 18.2 \\
\hline \multicolumn{3}{|l|}{ Fasting blood sugar } \\
\hline Normal (less than $99 \mathrm{mg} / \mathrm{dl}$ ) & 45 & 81.8 \\
\hline Pre-diabetes $(100-125 \mathrm{mg} / \mathrm{dl})$ & 8 & 14.5 \\
\hline Diabetes & 2 & 3.6 \\
\hline \multicolumn{3}{|l|}{ Total cholesterol (TC) } \\
\hline Less than $200 \mathrm{mg} / \mathrm{dl}$ & 23 & 41.8 \\
\hline More than $200 \mathrm{mg} / \mathrm{dl}$ & 32 & 58.2 \\
\hline \multicolumn{3}{|l|}{ Triglyceride (TG) } \\
\hline Less than $150 \mathrm{mg} / \mathrm{dl}$ & 16 & 29.0 \\
\hline More than $150 \mathrm{mg} / \mathrm{dl}$ & 39 & 70.9 \\
\hline \multicolumn{3}{|l|}{ High-density lipoprotein (HDL) Male } \\
\hline Less than $40 \mathrm{mg} / \mathrm{dl}$ & 8 & 32 \\
\hline More than $40 \mathrm{mg} / \mathrm{dl}$ & 17 & 68 \\
\hline \multicolumn{3}{|l|}{ High-density lipoprotein (HDL) Female } \\
\hline Less than $50 \mathrm{mg} / \mathrm{dl}$ & 14 & 46. \\
\hline More than $50 \mathrm{mg} / \mathrm{dl}$ & 16 & 53.3 \\
\hline \multicolumn{3}{|l|}{ Waist circumference (Male) } \\
\hline More than $102 \mathrm{~cm}$ & 10 & 40 \\
\hline Less than $102 \mathrm{~cm}$ & 15 & 60 \\
\hline \multicolumn{3}{|l|}{ Waist circumference (Female) } \\
\hline More than $89 \mathrm{~cm}$ & 22 & 73.3 \\
\hline Less than $89 \mathrm{~cm}$ & 08 & 26.6 \\
\hline \multicolumn{3}{|l|}{ Hypertension } \\
\hline Less than $130 / 80 \mathrm{mmHg}$ & 45 & 89.0 \\
\hline More than $130 / 80 \mathrm{mmHg}$ & 6 & 10.9 \\
\hline \multicolumn{3}{|l|}{ Metabolic syndrome } \\
\hline Present & 30 & 54.5 \\
\hline Absent & 25 & 45.5 \\
\hline
\end{tabular}


In this study, only $10(18.2 \%)$ of the population had blood sugar above $100 \mathrm{mg} / \mathrm{dl}$. However, similar study was reported that the prevalence of type-2 diabetes was the same in young people with schizophrenia and their healthy peers [10]. Furthermore, a study conducted in UK, where increased risk of diabetes among mentally ill patients was reported [11] [12]. Increased cardio vascular disease (CVD) morbidity is also found in patients with mental disorders other than schizophrenia. In a sample of adult with psychotic symptoms, the risk for CVD was increased by $60 \%-70 \%$ in patients with mood disorder or post-traumatic stress disorder (PTSD) relative to the Framingham 10-year risk of CVD (10). Even though metabolic syndrome and cardiovascular risks are common among mentally ill patient, but we don't have any statistical report. According to this study, 32 (58.2\%) of population had increased TC (more than $200 \mathrm{mg} / \mathrm{dl}$ ), and $39(70.9 \%)$ of population had increased TG (more than $150 \mathrm{mg} / \mathrm{dl}$ ). Early detection of metabolic syndrome reduces the incidence of cardiovascular risk including diabetes, hypertension and cholesterol in future.

\section{Conclusion}

Patients with severe mental illnesses, particularly schizophrenia and mood disorders, have proved a higher prevalence of metabolic syndrome or its components compared with the general population. Regular monitoring of all features of metabolic syndrome is the cornerstone of its early detection and management. There is an urgent need to develop and implement effective programs to increase life expectancy in mentally ill patients. Further studies could examine the efficacy and effectiveness of weight-reducing interventions in lowering the risk for metabolic syndrome and subsequent cardiovascular-related morbidity and mortality in patients with mentally ill.

\section{Limitation of the Study}

There are number of limitations of this study, all most all data were collected from the medical records, unfortunately we didn't get smoking and alcohol details. We didn't compare the cardiovascular risk factors before and after starting anti-psychotic medication. Finally, we collected data from medical records those who are in anti-psychotic medications rather than different psychiatric disorder. As second generation antipsychotic medications are expensive and limited availability, most of our mentally ill patients are on first generation of anti-psychotic medications.

\section{Availability of Data and Material}

All data gathered during this study are included in this published article.

\section{Competing Interests}

The author declares that no competing interests. 


\section{Funding}

This research received no funding support

\section{Acknowledgements}

I thank all the staff from the mental health unit for their kind cooperation during the data collection.

\section{References}

[1] Papanastasiou, E. (2013) The Prevalence and Mechanisms of Metabolic Syndrome in Schizophrenia: A Review. Therapeutic Advances in Psychopharmacology, 3, 33-51.

[2] Ford, E.S., Giles, W.H. and Dietz, W.H. (2002) Prevalence of the Metabolic Syndrome among US Adults: Findings from the Third National Health and Nutrition Examination Survey. JAMA, 287, 356-359. https://doi.org/10.1001/jama.287.3.356

[3] Toalson, P., Ahmed, S., Hardy, T. and Kabinoff, G. (2004) The Metabolic Syndrome in Patients with Severe Mental Illnesses. The Primary Care Companion to the Journal of Clinical Psychiatry, 6, 152-158.

http://www.pubmedcentral.nih.gov/articlerender.fcgi?artid=514841\&tool=pmcentre z\&rendertype $=$ abstract https://doi.org/10.4088/PCC.v06n0402

[4] Umakanth, M. and Gadambanathan, T. (2018) Over Weight and Obesity among Mentally Ill Patients. Saudi Journal of Medical and Pharmaceutical Sciences, 4, 124-126.

[5] Mondelli, V., Anacker, C., Vernon, A.C., Cattaneo, A., Natesan, S., Modo, M., et al. (2013) Haloperidol and Olanzapine Mediate Metabolic Abnormalities through Different Molecular Pathways. Translational Psychiatry, 3, e208.

https://doi.org/10.1038/tp.2012.138

[6] Kato, M., Sotelo, J., de Guia, C., et al. (2003) Prevalence of the Metabolic Syndrome in Hispanic Patients with Mood Disorder: A Pilot Study. 156th Annual Meeting of the American Psychiatric Association, San Francisco, 17-22 May 2003, 17-22.

[7] Lee, J., Nurjono, M., Wong, A. and Salim, A. (2012) Prevalence of Metabolic Syndrome among Patients with Schizophrenia in Singapore. Annals Academy of Medicine, Singapore, 41, 457-462.

[8] Misiak, B., Frydecka, D., Łaczmański, Ł., Ślęzak, R. and Kiejna, A. (2014) Effects of Second-Generation Antipsychotics on Selected Markers of One-Carbon Metabolism and Metabolic Syndrome Components in First-Episode Schizophrenia Patients. European Journal of Clinical Pharmacology, 70, 1433-1441. https://doi.org/10.1007/s00228-014-1762-2

[9] Newcomer, J. (2007) Antipsychotic Medications: Metabolic and Cardiovascular Risk. The Journal of Clinical Psychiatry, 4, 8-13.

[10] Mitchell, A.J., Vancampfort, D., De Herdt, A., Yu, W.P. and De Hert, M. (2013) Is the Prevalence of Metabolic Syndrome and Metabolic Abnormalities Increased in Early Schizophrenia? A comparative Meta-Analysis of First Episode, Untreated and Treated Patients. Schizophrenia Bulletin, 39, 295-305.

https://doi.org/10.1093/schbul/sbs082

[11] Osborn, D.P., Wright, C.A., Levy, G., King, M.B., Deo, R. and Nazareth, I. (2008) Relative Risk of Diabetes, Dyslipidaemia, Hypertension and the Metabolic Syn- 
drome in People with Severe Mental Illnesses: Systematic Review and Metaanalysis. BMC Psychiatry, 8, 84.

http://www.ncbi.nlm.nih.gov/entrez/query.fcgi?cmd=Retrieve\&db=PubMed\&dopt=Cit ation\&list_uids=18817565\%5Cnhttp://www.ncbi.nlm.nih.gov/pmc/articles/PMC25706 60/pdf/1471-244X-8-84.pdf

[12] Scott, E.M., Hermens, D.F., White, D., Naismith, S.L., GeHue, J., Whitwell, B.G., et al. (2015) Body Mass, Cardiovascular Risk and Metabolic Characteristics of Young Persons Presenting for Mental Healthcare in Sydney, Australia. BMJ Open, 5, e007066. 